\title{
LENTES DE RECONHECIMENTO E LENTES DE DOMINAÇÃO: A NARRATIVA LITERÁRIA COMO FORMA DE (RE)DIRECIONAR O OLHAR DO DIREITO AO PARADIGMA DO OUTRO
}

\section{Thaís Maciel de Oliveira*}

Resumo: A partir de um contexto literário, busca-se fomentar uma harmonização do Direito com a Literatura com intuito de aproximar a imaginação literária da racionalidade pública, através da obra Senhora de José de Alencar. Portanto, através de uma pesquisa complexoparadoxal e pelo método de abordagem dialético, problematiza-se a delimitação dos papéis sociais diante de uma dialética do reconhecimento com o outro. Consequentemente, a anulação das identidades presentes na obra é uma discussão atual e que ainda causa exclusões e infelicidades em pleno século XXI.

Palavras-chaves: Direito; Diversidade; Gênero; Literatura; Reconhecimento.

\section{RECONNAISSANCE LENSES AND LENSES OF DOMINATION: THE LITERARY NARRATIVE AS A WAY OF (RE)DIRECT THE RIGHT TO THE OTHER PARADIGM}

\begin{abstract}
From a literary context, the aim is to promote a harmonization of the law with the Literature in order to bring the literary imagination of public rationality, through the work of José de Alencar Lady. Therefore, through a complex search-paradoxical and dialectical approach method, discusses-if the delimitation of social roles in front of a dialectics of recognition with the other. Consequently, annul the identities present in the work is a current discussion and that still cause exclusions and unhappiness in the 21 st century.
\end{abstract}

Keywords: Law; Diversity; Genus; Literature; Recognition.

\footnotetext{
* Mestranda bolsista CAPES/TAXA do Programa de Pós-graduação em Direito Stricto Sensu - Mestrado em Direitos Especiais da Universidade Regional do Alto Uruguai e das Missões - Campus Santo Ângelo, Rio Grande do Sul, Brasil. Pós-graduanda em Filosofia na Contemporaneidade pela URI-SA. Membro do grupo de pesquisa: "Direito, Cultura e Religião: conexões e interfaces" (Linha I - Direito e Multiculturalismo), cadastrado no CNPQ e vinculado ao Programa de Pós-Graduação Stricto Sensu em Direito, Mestrado e Doutorado da URI, campus Santo Ângelo. Bacharela em Direito pela Instituição de Ensino Superior de Santo Ângelo CNEC/IESA. E-mail: adv.thaismaciel@gmail.com.
} 


\section{INTRODUÇÃO}

A partir de uma perspectiva literária, o presente artigo busca aproximar o Direito da Literatura com o intuito de instigar uma aproximação do leitor com temas sobre diversidade de gênero, relação entre integração da sociedade e anulação da individualidade. Desse modo, a partir do acostamento entre Direito e Literatura se buscou avizinhar o abstrato do concreto, com vistas à humanização do Direito.

A reflexão fornecida pela obra Senhora, através do método de raciocínio dedutivo auxilia a compreensão da sociedade a luz dos conceitos como as relações de poder, dicotomia de gênero e a construção política do sujeito. Igualmente, a pesquisa pela abordagem qualitativa auxilia a compreensão e aproximação do mundo fictício e do real. Nesse segmento, através de uma pesquisa complexo-paradoxal, visa-se questionar as ambiguidades presentes na obra, na figura de Aurélia e Fernando Seixas, os analisando como seres de linguagem e que reproduzem os comportamentos delimitados pela sociedade local. Portanto, o método de abordagem dialético auxilia na compreensão dos contrates presentes na obra e problematiza o contexto que os personagens estavam inseridos.

Com efeito, os personagens da obra Senhora, Aurélia e Fernando Seixas, são estudados em razão de suas peculiaridades e contradições. A construção identitária do sujeito também entra no objetivo do presente estudo, diante do enfoque cultural e social que o trabalho propõe. Como resultado das delimitações sociais, o indivíduo é problematizado diante da anulação de sua individualidade em prol do interesse coletivo.

Nesse aspecto, as delimitações dos papéis sociais entram em pauta frente aos conceitos de masculinidade e feminilidade presentes na narrativa. Portanto, a narrativa ficcional tem uma importante contribuição para o século XXI, principalmente frente a matriz colonial reminiscente e diante das questões de discriminações e exclusões que a contemporaneidade ainda enfrenta. Consequentemente, a sociedade da aparência ainda anula individualidades em pleno século XXI, portanto a discussão sobre a diversidade de gênero, os papais sociais e a cultura patriarcal, constituem conceitos fundamentais para instigar uma dialética do reconhecimento e do respeito com o outro. 


\section{VIÉS RELACIONAL ENTRE DIREITO E LITERATURA}

A busca pela humanização do direito constitui uma importante perspectiva hermenêutica do século XXI. A produção de saberes necessita da superação das expectativas coloniais, pois a reprodução de verdades cristalizadas, enraizadas em preconceitos não comporta a extensa sociedade multicultural da contemporaneidade. Logo, um dos desafios da atualidade concentra-se em fomentar um pensar diverso dos estereótipos culturais.

A aproximação do direito com a literatura, nesse sentido, possibilita a contextualização de questões centrais como: gênero, diversidade identitária e reforma do pensamento social, de uma maneira mais empática ao leitor. Portanto, essa forma de olhar o direito a partir de uma concepção humanista e pluralista, difere do olhar do senso comum da racionalidade pública.

Assim, a partir da imaginação literária é possível compreender o Direito além de duas concepções formais e estruturais. Ou seja, a narrativa literária fornece uma maior liberdade, podendo redefinir campos de estudo e análise.

“A experiência literária está muito mais atenta à complexidade e pluralidade dos significados da vida social e, por isso se vale de uma narrativa cuja forma e conteúdo são mais sensíveis à tal diversidade" (CHUEIRI, 2009, p. 234). Com efeito, a imaginação literária permite a compreensão de um contexto social diferente da realidade à que estão inseridos. Atribuindo a emoção um papel imprescindível para interpretação do diferente.

A literatura como visão humanista do direito é compreendida "como uma nova forma de redescoberta da própria sensibilidade e da sensibilidade como forma de compreensão além do pensamento" (WARAT, 2010, p. 119). Logo, a literatura representa uma ponte essencial para a concretização da justiça social.

Segundo Derrida, a Literatura é o lugar no qual se experiência/experimenta o problema com a essência da linguagem, com a verdade e com a essência, com a linguagem da essência em geral. A experiência literária questiona e ao questionar perturba a autoridade e a pertinência da questão acerca da essência, qual seja, aquela que pergunta "o que é...". Assim, a importancia da Literatura para o Direito e a Justiça reside, primeiramente, nessa maneira perturbadora com a qual ela atravessa para a linguagem da essência e da verdade. Para esse autor o Direito e a Literatura repartem as mesmas condições de possibilidade, o que significa que a origem do Direito é também aquela da Literatura, a qual, em última análise, é uma não-origem, na medida em que se mantém em suspensão e a ela não se tem acesso (CHUEIRI, 2009, p. 234). 
Nessa toada, direito e literatura possuem o mesmo lócus, ou seja, como produtos da linguagem, são construções da imaginação humana. Destarte, a função da sensibilidade da literatura "além de proporcionar ao ser humano uma existência mais poética [...] a literatura instaura experiências em quem lê, de modo a exercer diferentes tipos de impactos, porque é problematizada em diferentes níveis e de diferentes situações" (DUARTE; MADERS, 2017, p. 514-516).

"O Direito e Literatura é um novo campo de possibilidades para questões formais e materiais que afligem tanto o Direito quanto a Literatura" (CHUEIRI, 2009, p. 235). O direito, nesse aspecto, se aproxima da imaginação literária diante das reivindicações do saber contemporâneo. Além disso:

\footnotetext{
Pelas infinitas possibilidades de interpretação, pela não fragmentação do homem, pela valorização da emoção, pela abertura ao pensar diferente, a literatura nos mostra a urgência de reintegrarmos o homem. A vivência da leitura de um conto ou um poema não é analisada em partes, primeiro racionalmente e podeis emocionalmente. Mente, alma, corpo e coração são implicados ao mesmo tempo, conjuntamente e é daí que se extrai sua beleza, que se experimenta o prazer. (MOREIRA; OLIVEIRA, 2015, p.16).
}

A obra literária serve como subsídio para reflexão moral e social, permitindo o diálogo sobre diversas questões problemáticas da vida contemporânea. Nesse sentido, a imaginação literária interliga o leitor ao personagem, aflorando sentimentos ao leitor e o conectando intimamente com a literatura, promovendo a identificação e simpatia, do leitor com os personagens da obra. Portanto, a importância da aproximação do direito com a literatura reside no fato que os dois são resultados da linguagem e da criação humana. Logo, os dois são construções culturais que juntos podem fomentar uma forma de justiça social.

\subsection{A Personagem Aurélia e o Padrão Hegemônico}

Nessa tangente, a obra literária Senhora, de José de Alencar, possibilita a compreensão de ideologias e posicionamentos do século XIX, igualmente como os costumes e práticas sociais normatizados na época. Aurélia, personagem central desse Romance, personifica uma inversão de papéis, ao assumir atitudes masculinizadas na trama. Entretanto, ao longo na obra a personagem sofre diante das convenções sociais. 
Durante seu crescimento, a personagem é edificada com base na ideologia de que o matrimônio representa felicidade. Dessa forma, ao adquirir riqueza, em uma inversão das relações de poder, "compra” seu marido, em uma ambiguidade de atitudes sinalizando a busca pela felicidade diante das pressões sociais.

Aurélia em várias partes da obra salienta a necessidade de reconhecimento social:

Daí encaminhou-se ao piano, que é para as senhoras como o charuto para os homens, um amigo de todas as horas, um companheiro dócil, e um confidente sempre atento. Ao abrir o instrumento, lembrou-se de que não era próprio a uma noiva de véspera entregar-se a esse passatempo, quando vizinhos e criados, todos deviam supô-la àquela hora engolfada na felicidade de amar e ser amada. Ah! Ela não conhecia essa aurora mística do amor conjugal, que se lhe transformara em vigília de angústia e desespero. Mas adivinhava qual devia ser a transfusão mútua de duas almas, e compreendia que, ávidas uma da outra, não se podiam alhear em estranho passatempo (ELENCAR, 1997, p. 53)

O confronto existente em várias partes da obra; do indivíduo com a sociedade, simboliza os aspectos da pressão social que a sociedade apregoa na delimitação de estereótipos. O reconhecimento do outro, nesse sentido, é feito a partir do lugar social que ocupa, ou seja, a sociedade delimita e constrói fronteiras entre aqueles que simbolizam o padrão cultural, a norma. Nesse termos, os outros são denominados a partir desse referencial de normal.

O desenvolvimento da identidade pessoal de um sujeito está ligado fundamentalmente à pressuposição de determinadas formas de reconhecimento por outros sujeitos; pois, com efeito, a superioridade da relação interpessoal sobre a ação instrumental consistiria manifestamente em que ela abre reciprocamente para os sujeitos comunicantes a possibilidade de se experienciar em seu parceiro de comunicação como o gênero de pessoa que eles reconhecem nele a partir de si mesmos (HONNETH, 2009, p. 78).

Entretanto, nenhuma cultura "ou tradição específica pode colonizar o entendimento sobre o bom, relativizando as outras realidades culturais e estabelecendo seu próprio império de valores" (LUCAS, 2013, p. 238). Com base nessa compreensão, desenvolvimento da identidade pessoal do indivíduo está ligado ao reconhecimento por outros sujeitos.

Destarte, o reconhecimento é um importe fator na edificação do indivíduo. Charles Taylor no seu livro Multiculturalismo, também pontua sobre a importancia do correto reconhecimento para o indivíduo. Já que seu incorreto reconhecimento por parte da sociedade pode ocasionar uma auto depreciação: 


\begin{abstract}
A importancia do reconhecimento é universalmente admitida, de uma forma ou de outra: no plano íntimo, estamos todos conscientes de como a identidade pode ser formada ou deformada no decurso da nossa relação com os outros-importantes; no plano social, temos uma política permanente de reconhecimento igualitário. Ambos os planos sofreram a influência do ideal de autenticidade, à medida que este foi amadurecendo, e o reconhecimento joga um papel essencial na cultura que surgiu à volta desse ideal (TAYLOR, 1998, p.56).
\end{abstract}

De fato, constitui realidade indubitável, tanto na obra quanto na atualidade, que as práticas sociais reiteram discursos de gênero extremamente fundamentalistas, que segregam direitos em prol de uma verdade particular. Essa verdade particular da cultura dominante é perpassada como universal para sociedade. É pontuada como anterior a cultura, como princípio basilar.

Em suma:

\begin{abstract}
Definir alguém como homem ou mulher, como sujeito de Gênero e de sexualidade significa, pois, necessariamente, nomeá-lo segundo as marcas distintivas de uma cultura - com todas as consequências que esse gesto acarreta: a atribuição de direitos ou deveres, privilégios ou desvantagens. Nomeados e classificados no interior de uma cultura, os corpos se fazem históricos e situados (LOURO, 2013, p. 95).
\end{abstract}

Percebe-se que, as convenções, representações e símbolos culturais interferem na construção da identidade do indivíduo. Dessa forma, a norma heterossexual representa requisito para pertencer a um grupo social. Nesse aspecto, o vínculo social que proporciona formas de reconhecimento é responsável pela organização social vigente.

Com efeito, por mais que em várias passagens da obra Aurélia demonstre uma ruptura dos papéis sociais, a personagem sinaliza angústias diante das práticas sociais, consequentemente, o estereótipo de submissão está incluso em sua subjetividade. Ou seja, mesmo representando papéis diversos da perspectiva da época, Aurélia está incluída naquela sociedade. Logo, conforme as convenções sociais pressionam, a personagem cumpre sua função social. 


\subsection{Fernando Seixas e as visões de Masculinidade Coloniais}

O personagem Fernando Seixas é representado como um homem ambíguo, demonstrando facetas positivas e negativas da moral. A simbologia em torno do personagem personifica o confronto do indivíduo com seus desejos e padrões impostos pela sociedade.

A oposição dos estereótipos presente na obra, principalmente na figura do personagem Fernando é representada por sua busca em concretizar suas ambições e sua inclusão na delimitação da sociedade como normalidade do gênero masculino. A relação de poder presente entre os personagens Aurélia e Fernando muitas vezes apresenta contradições. Em muitas passagens da obra, Aurélia simboliza o domínio das relações de poder com base em seu enriquecimento.

A masculinidade do personagem ao incorporar as práticas sociais exigidas pela sociedade transpassa por mudanças de comportamento. A dialética transmitida pela obra, evidencia uma crítica a práxis social da vida conjugal. Nessa concepção, a diversidade identitária sob o enfoque cultural é relegada em prol do interesse coletivo. Ou seja, por mais que no início da obra Fernando reitere seu amor por Aurélia, a necessidade de pertença social supera esse amor.

Nessa toada, nota-se ao longo da obra a relação especial reflexiva entre o eu e os outros. Logo, o indivíduo como produto dessa relação reflexiva, absorve conceitos e significados através da linguagem social.

\footnotetext{
Nenhuma experiência é mais central que essa relação ao outro pela qual um e outro se constituem como sujeitos. Mas seria artificial opor essa relação privada à vida pública. Todos os indivíduos estão presos numa rede de papéis, existem para outrem e o encontro do outro jamais se opera em terreno aberto, como numa cena de filme onde dois personagens surgissem, um diante do outro, em um cenário vazio. É necessário sobretudo que o reconhecimento do outro como sujeito leve a participar dos esforços do outro para se libertar das exigências que o impedem de viver como sujeito (TOURRAINE, 1994, p. 292).
}

Essa homogeneização através do poder e da linguagem visa padronizar o indivíduo facilitando o poder da maioria sobre o sujeito individualizado. Essa unificação das características individuais em prol de uma maioria é embasada em fundamentalismos que apregoam a edificação de estereótipos. A sociedade, nesse aspecto, delimita o comportamento dos seus cidadãos, e os enquadra em posições de hierarquia conforme interesse da cultura local. 
Nesse enfoque, percebe-se ao decorrer da obra, os anseios da sociedade em naturalizar os papeis de gênero, considerando-a como algo biológico do ser humano, anterior a cultura. Esse argumento moralista que apregoa a dicotomia de gênero como verdade universal, participa ativamente da construção identitária do indivíduo (BUTLER, 2017). Quem não aceita essas ideologias estereotipadas não é integrado no grupo social, passando a ser sujeito à margem da sociedade ou socialmente discriminado.

Principalmente na obra referenciada, percebe-se em vários aspectos a necessidade do enquadramento social por parte do indivíduo. Tanto os personagens Aurélia e Fernando Seixas anulam sua individualidade em face dos papeis sociais.

Por derradeiro, a coisificação de Seixas é visualizado na obra quando Aurélia adquire o personagem. Nesse aspecto, Seixas constituí o objeto de desejo da personagem Aurélia. Consequentemente, a personagem feminina de acordo com a cultura patriarcal, apenas alcança sua plenitude a partir do casamento. Logo, a plenitude referenciada na obra representa a necessidade dos sujeitos em construir sua identidade social.

Com efeito, os princípios morais enaltecidos na obra têm uma inter-relação com os anseios da sociedade. Ou seja, os valores morais aceitos pela sociedade estão relacionados com a fonte de poder dominante local. Essa regulamentação dos valores morais normatizados pelo coletivo apresenta raízes históricas que variam culturalmente de acordo com a política de cada época.

\footnotetext{
A formação da identidade do ser faz parte do diálogo e das lutas permanentes com os outros, enquanto que na esfera pública a noção das identidades se forma pelo diálogo e contribui ao desempenho de um papel crescente para a política do reconhecimento igualitário. Essa política refere-as à valorização da dignidade em vez de honra, bem como se refere ao desenvolvimento de uma noção moderna de identidade, a qual originou uma política de diferença, calcada no reconhecimento do caráter singular de cada um (SANTOS; LUCAS, 2015, p. 109).
}

Neste aspecto, a construção da identidade do indivíduo leva a análise tanto dos sistemas socioculturais que modelam a moral, quanto a interpretação do considerado normal em cada momento histórico. Portanto, o modo pelo qual os papéis de gênero são estruturalizados revelam as formas de poder que sujeitam os indivíduos em determinada época (CONNEL; PEARSE, 2015). 
Nesse aspecto, percebe-se que os caminhos histórico-culturais são vinculados pela hegemonia da racionalidade dominante local, implicando a recriação de identidades conforme a matriz ocidental. Rita Segato assim dispõe sobre o discurso da matriz ocidental:

\begin{abstract}
De acordo com o padrão colonial moderno e binário, qualquer elemento, para alcançar plenitude ontológica, plenitude de ser, deverá ser equalizado, ou seja, equiparado a partir de uma grade de referência comum ou equivalente universal. Isto produz o efeito de que qualquer manifestação da alteridade constituirá um problema, e só deixará de fazê-lo quando peneirado pela grade equalizadora, neutralizadora de particularidades, de idiossincrasias (SEGATO, 2012, p. 122).
\end{abstract}

Entretanto, diante da instabilidade da sociedade contemporanea há necessidade de instigar e recriar novos enfoques epistemológicos, que não priorizem apenas um lócus histórico, mas que compreendam as identidades integrando todos os aspectos culturais e históricos locais. Esse entendimento é primordial para não se dicomotizar e segregar identidades. Nesse exposto, tanto a matriz ocidental como a literatura e o direito são construções da mente humana, representam momentos históricos e culturais reiterados através da linguagem ou da escrita.

\title{
2.3 Ambiguidades Presentes na Obra
}

A obra literária Senhora apresenta uma narrativa patriarcal e patrimonialista, assinalando que o empoderamento feminino apenas se verifica na aquisição de patrimônio. Destarte, a personagem Aurélia ao adquirir uma postura de submissão ao final da narrativa volta aos ideais apregoados pela sociedade da época.

Com efeito, a reflexão da obra subjaz o pensamento colonial que a mulher apenas alcança sua completude quando retorna ao domínio dos homens. Entretanto, mesmo diante dessa contradição, a obra Senhora:

\footnotetext{
Ajuda a compreender algumas representações construídas sobre homens e mulheres numa perspectiva pedagógica que instruiu o leitor, por meio de modelos exemplares, a compreender o mundo e a si, a pensar, a sentir e a se comportar. Apresenta um conhecimento sobre as relações entre os gêneros, ao abordar as regras sociais da época em relação às experiências amorosas e às práticas moralmente aceitas, auxiliando na formação de novos cidadãos. Suas figuras idealizadas veiculam mensagens na intenção de forjar uma realidade para além da ficção, orientando e ajudando as pessoas a compreender como deveriam se relacionar ou como se esperava que elas se relacionassem na nova conjuntura social (BORGES, 2012, p. $312)$.
} 
Por derradeiro, a ambiguidade presente na obra da racionalidade em contraposição a emoção tem um caráter pedagógico para auxiliar a construção dos papeis de gênero. Neste dispersão, questionar o real e o factual no interior de uma cultura fundamentalista põe em questão a estrutura que articula essas identidades.

A construção do sujeito, nesse exposto, como processo da socialização, é reiterado através das narrativas comunitárias. Logo, a descontinuidade ou temporalidade dos processos culturais tornam em voga as questões identitárias. Desse modo, o paradigma identitário apresenta características dinâmicas e multifacetadas.

Segundo Warat:

\begin{abstract}
Em nome da igualdade elimina-se o direito à diferença. As formas sociais democráticas necessitam do reconhecimento de que todos os homens são diferentes. Os homens não lutam pela igualdade. Agrupam-se para lutar pelo reconhecimento de alguma diferença. Usaria para a democracia o lema: autonomia, desigualdade e indeterminação. A partir destes três elementos podemos pensar em outro tipo de representação imaginárias comprometidas com o termo democracia (WARAT, 2004, p. 327).
\end{abstract}

Essa homogeneização através do poder presente na obra, padroniza o indivíduo facilitando o poder da maioria sobre o sujeito individualizado. Essa unificação das características individuais em prol de uma maioria é embasada em fundamentalismos que apregoam a edificação de estereótipos. A sociedade, nesse aspecto, delimita o comportamento dos seus cidadãos, e os enquadra em posições de hierarquia conforme interesse da cultura local.

\title{
3 CONTRIBUIÇÕES PARA O SÉCULO XXI
}

A relação da literatura com do direito possibilita uma visão mais humanista do contexto social em que se referência. Assim, a aproximação do abstrato e do concreto contribuem para edificação de leitores sensíveis aos questionamentos e costumes da época. Possibilitando uma importante reflexão com as questões de gênero e a superação das perspectivas coloniais.

A obra citada apresenta uma importante reflexão sobre a sociedade da aparência. Os personagens Aurélia e Fernando Seixas anulam sua individualidade em busca de suprir os 
anseios da sociedade em que estavam inclusos. Esta caracteristica de perder sua individualidade em prol do interesse coletivo ainda perpassa o imaginário da sociedade do século XXI. Ou seja, a cultura através da linguagem reitera padrões e hierarquias sociais.

Entretanto, a miscigenação de identidades e pluralidades de culturas consubstanciam a sociedade multicultural contemporanea. Nesse aspecto, as identidades se caracterizam por representar uma totalidade de um conjunto, uma diferença comum. Assim, brilhantemente Eligio Resta clarifica sobre identidade:

O espaço da identidade está sempre em percurso que vai de uma coisa a outra, que necessita do outro para se realizar como identidade: assim, posso dizer sobre o ser "eu" ao mesmo tempo em que continuo a ser italiano, mas posso afirmar também que sou eu porque não sou austríaco ou Imperador da China (RESTA, 2014, p. 24).

Por derradeiro, as múltiplas identidades posicionam a forma de ver o mundo a partir da diferença. Portanto, a contemporaneidade comporta o desafio de conviver com o diferente em uma mesma comunidade. Nesse aspecto, a comunicação é essencial para a abertura com o outro em uma sociedade complexa multicultural. As diversas culturas e identidades cingem a contemporaneidade e demandam respeito aos indivíduos como sujeito de direitos.

\begin{abstract}
A incapacidade de enxergar o outro em suas especificidades e simbologias impossibilita o diálogo e vem revelando a fragilidade do ser humano, o que deixa cada vez mais longínqua a solução para a harmonização das diferenças culturais e abre caminho para fundamentalismos de qualquer sorte. (MEDEIROS, 2009, p. 588).
\end{abstract}

O sistema patriarcal presente na obra ainda constituí ideologia padrão da sociedade contemporanea. Ou seja, a construção política do sujeito ainda é embasada pela dicotomia epistemológica. Logo, o padrão normativo reiterado pela cultura representa as relações dominantes que regularizam os processos de interação.

Segundo Butler:

\footnotetext{
Uma das maneiras pelas quais o poder é ocultado e perpetuado é pelo estabelecimento de uma relação externa ou arbitrária entre o poder, concebido como representação ou dominação, e o sexo, concebido como energia vigorosa mas toldada, à espera de libertação ou auto expressão autêntica (BUTLER, 2017, p. 166-167).
}

Percebe-se diante do intento que os papeis sociais do indivíduo são produções fictícias das relações de poder. Esta fantasia do que é considerado normal e o que é diferente 
são instituídos e inscritos sobre a superfície dos corpos (LOURO, 2013). Com efeito, a noção de identidade certa e errada é revestida pelas práticas culturais e discursivas de cada época.

Como resultado desse processo cultural, o indivíduo que não se enquadra no padrão segue em conflitos sociais frente à busca por reconhecimento como sujeitos de direitos em um Estado Democrático de Direito. O Estigma social sob pretensões mitigadas representa a lógica dicotômica que conceptualiza as relações de poder.

Nesse sentido, caudatário de processos históricos e culturas de segregação, a heteronormatividade sexual qualifica-se como uma herança epistemológica de discursos fundamentalistas de poder. A compreensão dos processos de edificações de verdades absolutas e intransigíveis deflagram os discursos e repetições pelos quais as regras são criadas e reiteradas.

\section{NARRATIVA EPISTEMOLÓGICA VOLTADA À DIVERSIDADE}

A diversidade identitária que a obra Senhora possibilita a reflexão, refere-se na compreensão da complexidade que consubstancia a identidade do indivíduo. Portanto, a busca pelo indivíduo de se integrar na sociedade resulta na anulação de sua individualidade. Nesse sentido, realizando uma interligação com a sociedade atual, os indivíduos precisam do reconhecimento coletivo para se sentirem incluídos na sociedade (HONNETH, 2009).

Por derradeiro, o indivíduo como parte integrante da sociedade, precisa se enquadrar aos modelos propostos, para se tornar um sujeito de direitos humanos. Judith Butler argumenta sobre o processo de edificação cultural:

\footnotetext{
Um processo baseado em características físicas que são vistas como diferenças e às quais se atribui significados culturais. Afirma-se e reitera-se uma sequência de muitos modos já consagrada, a sequência sexo-gênero-sexualidade. $\mathrm{O}$ ato de nomear o corpo acontece no interior da lógica que supõe o sexo como um dado anterior a cultura e lhe atribui um caráter imutável, a-histórico e binário. Tal lógica implica que esse dado sexo vai determinar o gênero e induzir a uma única forma de desejo. Supostamente, não há outra possibilidade senão seguir a ordem prevista (BUTLER, 2017, p. 9).
}

Nesse enfoque, falar sobre identidade, reconhecimento e gênero é essencial para compreender a complexidade do indivíduo em suas múltiplas expressões. Warat igualdade analisa sobre as construções simbólicas da sociedade e seus reflexos no indivíduo: 
Temos que aceitar que é na própria sociedade que podemos encontrar a origem das significações por elas criadas. Estou referindo-me à possibilidade de repensar a sociedade como auto-instituinte de suas significações, intrinsecamente histórica, capaz de questionar permanentemente suas próprias condições de existência e reconhecer-se como um lugar de criatividade incontrolável. Ou seja, uma nova sociedade que possa escapar às condições que determinaram sua alienação (WARAT, 2004, p. 328).

Nessa toada, a construção de sua identidade é refletida pelo meio social em que está inserido. Portanto, uma narrativa voltada à diversidade, não delimita estereótipos e possibilita a edificação do indivíduo diversa da concepção dicotômica dos papéis sociais (BUTLER, 2017). A linguagem, nesse seguimento, constituí um importante fator de socialização e de criação de padrões. As relações de dominação, portanto, regulam as narrativas de gênero:

\begin{abstract}
Gênero é sempre um feito, ainda que não seja obra de um sujeito tido como preexistente à obra. No desafio de repensar as categorias do gênero fora da metafísica da substância, é mister considerar a relevância da afirmação de Nietzsche, em Genealogia da moral, de que não há ser por trás do fazer, do realizar e do tornarse; o fazedor é uma mera ficção acrescentada à obra - a obra é tudo. Numa aplicação que o próprio Nietzsche não teria antecipado ou aprovado, nós afirmaríamos como corolário: não há identidade de gênero por trás das expressões do gênero; essa identidade é performaticamente constituída, pelas próprias expressões tidas como seus resultados (BUTLER, 2017, p. 56).
\end{abstract}

Os estereótipos sociais, nesse sentido, reduzem o indivíduo em uma qualificação reducionista de sua subjetividade. Entretanto, a complexidade do ser não comporta uma simplista qualificação estereotipada. Consequentemente, em virtude da diversidade de identidades presentes hoje na sociedade, é necessário um mútuo reconhecimento com o outro, para efetivamente dialogar em uma sociedade altera. Principalmente em um ambiente democrático, é necessário possibilitar não só os deveres do sujeito, mas também seus direitos.

$\mathrm{O}$ conhecimento, portanto, forja-se diante da cultura e das relações dominantes. $\mathrm{Ou}$ seja, a cultura, o saber, a literatura e o direito são linguagem, são criações humanas. O pensar a diversidade a partir do outro, nessa ótica, reconhece a extensa diversidade cultural que consubstancia a contemporaneidade. A reflexão que a obra propõe de uma perspectiva voltada às diferenças é primordial diante do panorama brasileiro atual.

Por derradeiro, a sociedade contemporanea é ambientada por indivíduos complexos e heterogêneos. Logo, a compreensão sobre as múltiplas formas de identificação constitui base para uma política efetiva de direitos humanos. Direcionar o olhar através das diferenças identitárias representa um olhar para os direitos humanos voltados para as múltiplas formas de 
reconhecimento. Ou seja, atribui como lente o paradigma o outro, diverso e plural. Essa pluralidade é primordial para pensar em alteridade sem fronteiras. Do contrário, apenas reitera um discurso hegemônico reminiscente.

A questão da diversidade de gênero representa uma questão central da contemporaneidade. Desse modo, a diversidade identitária com seu consequente reconhecimento constituem a quintessência para constituição de uma sociedade multicultural e intercultural. Principalmente em um Estado Democrático de Direito, a diferença precisa ser cingida a um patamar de respeito e reconhecimento para poder proporcionar uma eficaz política de direitos humanos garantidos pela Constituição da República Federativa do Brasil.

\section{CONCLUSÃO}

A contemporaneidade comporta o desafio de viver com diversas identidades e culturas em um mesmo local. Consequência da globalização a miscigenação de culturas constitui caracteristica da sociedade do séxulo XXI. Portanto, a temática da alteridade, reconhecimento e respeito constituí base para uma sociedade democrática de direito.

Nesse contexto, a diversidade de gênero e os papéis sociais constituem dois temas presentes e recorrentes no Brasil atual. Diante da sociedade pluralista que permeia a sociedade do século XXI, questões sociais se tornam cada vez mais evidentes e críticas. Ou seja, na medida em que essas pluralidades se multiplicam novos direitos são reivindicados.

Salienta-se que a linguagem patriarcal como edificadora de padrões e estereótipos presentes na obra, ainda constituí ferramenta basilar na reiteração de discriminações e exclusões na sociedade contemporanea. A cultura com seu princípio de pertença causa infelicidades e segregações. Nesse aspecto, denota-se pela obra estudada que os papéis sociais são construções linguísticas, assim como a literatura e o direito.

Por derradeiro, apregoa-se, nesse intento, que a edificação de estereótipos, a dicotomia de gênero são produções da imaginação humana. Logo, redimir o preconceito significa desconstruir o padrão heteronormativo na sociedade. Ou seja, a partir da construção de sujeitos sociais críticos, é possível analisar as influências que edificam a delimitação dos estereótipos, na sociedade. Por consequência, compreendendo que os papéis sociais são construções linguísticas de uma cultura dominante, é possível problematizar esse sistema histórico de dominação e subjugação. 
A análise literária, nesse sentido, possibilita a discussão acerca da temática dos papéis sociais, da diversidade de gênero e das relações de poder. Dessa forma, a partir da narrativa em torno dos personagens Aurélia e Fernando Seixas é possivel questionar o papel das relações de poder na edificação dos estereótipos dominantes, assim como analisar o processo cultural que envolve o reconhecimento das identidades.

A epistemologia do padrão normativo revela os processos definidores de identidades. Logo, conclui-se que o processo de identificação do indivíduo parte da ação reflexiva do eu com o outro. O coletivo, nesse sentido, adapta o indivíduo a sua semelhança, sob pena de não pertencer a nenhum lócus social. Ou seja, sua individualidade é anulada em prol do interesse coletivo.

Doravante a desconstrução de identidades consideradas normais, sua percepção como processo ideológico das relações de poder constitui base para uma cultura de direitos humanos. A narrativa ficcional demonstra a busca dos personagens em suprir os anseios da sociedade da época, e como a sociedade acaba anulando suas individualidades.

A sociedade da aparência, nesse aspecto, é produto da matriz colonial que reitera discriminações. Consequentemente, esse conceito de identidade apresenta reminiscência da cultura patriarcal, que embasa o padrão hegemônico como verdade universal.

O pensar a diversidade a partir do outro, nessa ótica, reconhece a extensa diversidade cultural que consubstancia a contemporaneidade. Ou seja, significa (re)direcionar o olhar para a diversidade como sinal de mudança e (re)direcionar as lentes do reconhecimento voltado ao respeito para com o outro. É inegável que a cultura edifica lentes que influenciam as relações pessoais, porém é necessário compreender a importância do reconhecimento para um paradigma de não discriminação.

Dessa forma, diante da complexidade e miscigenação de culturas que constituem as identidades atuais, uma narrativa epistemológica voltada ao paradigma do outro significa um olhar pragmático a partir do reconhecimento. A diversidade de gênero e as diferenças identitárias fazem parte do pensar social, portanto questionar as relações de poder dominantes e a linguagem que fundamenta discriminações são primordiais para edificar esse olhar humanista que o artigo se propõe. 


\section{REFERÊNCIAS}

ALENCAR, José de. Senhora. Rio de Janeiro: Ediouro, 1997.

BORGES, Valdeci Rezende. Gênero e mercado matrinomial em Senhora de José de Alencar. Projeto História: Revista do Programa de Estudos Pós-Graduados de História, v. 45, 2012. Disponível em: < https://revistas.pucsp.br/index.php/revph/article/view/15016> Acesso em: 15 ago. 2018.

BUTLER, Judith. Problemas de Gênero: feminismo e subversão da identidade. Tradução Renato Aguiar. - 13 a ed. - Rio de Janeiro: Civilização Brasileira, 2017.

CHUEIRI, Vera Karam. Direito e Literatura.In: BARRETTO, Vicente de Paulo (Coord.) Dicionário de Filosofia do Direito. 2. reimp. São Leopoldo: Unisinos, 2009.

CONNELL, Raewyn; PEARSE, Rebecca. Gênero: uma perspectiva global. São Paulo: Versos, 2015.

DUARTE, Isabel Cristina Brettas; MADERS, Angelita Maria. O direito pelos olhares de Palomar. Anamorphosis: Revista Internacional de Direito e Literatura, v. 3, n. 2, p. 489-518, 2017. Disponível em: <https://dialnet.unirioja.es/servlet/articulo?codigo=6255932> Acesso em: 20 jul. 2018.

HONNETH, Axel, Luta por reconhecimento: a gramática moral dos conflitos sociais. Tradução de Luiz Repa; apresentação de Marcos Nobre. - $2^{\circ}$ ed. - São Paulo: Editora 34, 2009.

LOURO, Guacira Lopes. Um corpo estranho - ensaios sobre sexualidade e teoria queer. 2 ed. - Belo Horizonte: Autêntica Editora, 2013.

LUCAS, Doglas (org.). Pós-colonialismo, pensamento descolonial e direitos humanos na América Latina. - Santo Ângelo: FURI, 2014.

LUCAS, Doglas César. Direitos Humanos e Interculturalidade: um diálogo entre a igualdade e a diferença. Ijuí: Editora Unijuí, 2013.

MOREIRA, Nelson Camatta; OLIVEIRA, Juliana Ferrari de. Direito e literatura: e os múltiplos horizontes de compreensão pela Arte. Ijuí: Ed. UNIJUÍ, 2015.

Multiculturalismo: examinando a política de reconhecimento. Lisboa: Instituto Piaget, 1994.

RESTA, Eligio. Percursos da identidade: uma abordagem jusfilosófico. Ijuí: Ed. Unijuí, 2014.

SANTOS, André Leonardo Copetti; LUCAS, Doglas Cesar. A (in)diferença no direito. Porto Alegre: Livraria do Advogado Editora, 2015.

SEGATO, Rita Laura. Gênero e colonialidade: em busca de chaves de leitura e de um vocabulário estratégico descolonial. E-cadernos ces, n. 18, 2012. Disponível em: <https://journals.openedition.org/eces/1533 >. Acesso em: 12 jul. 2018. 
TAYLOR, Charles. A política de reconhecimento. In. Taylor, Charles. Multiculturalismo: examinando a política de reconhecimento. Lisboa: Instituto Piaget, 1998.

TOURRAINE, Alain. Iguais e Diferentes. Poderemos viver juntos. Tradução Carlos Aboim de Brito. Lisboa: Instituto Piaget, 1997.

WARAT, Luis Alberto. A rua grita Dionísio. Direitos humanos da alteridade, surrealismo e cartografia. Rio de Janeiro: Lumen Juris, 2010.

WARAT, Luis Alberto. Epistemologia e Ensino do Direito O Sonho Acabou. Florianópolis: Fundação Boiteux, 2004. 